\title{
Transforming growth factor- $\beta 1$ small interfering RNA inhibits growth of human embryonic lung fibroblast HFL-I cells in vitro and defends against radiation-induced lung injury in vivo
}

\author{
ZHONGHUA LU $^{1 *}$, YAN MA $^{1 *}$, SHUYU ZHANG $^{2}$, FENJU LIU $^{2}$, MEIZHEN WAN $^{1}$ and JUDONG LUO ${ }^{1,2}$ \\ ${ }^{1}$ Department of Radiotherapy, Changzhou Tumor Hospital, Soochow University, Changzhou, Jiangsu 213001; \\ ${ }^{2}$ Jiangsu Provincial Key Laboratory of Radiation Medicine and Protection, School of Radiation Medicine and Protection, \\ Soochow University, Suzhou, Jiangsu 215123, P.R. China
}

Received December 24, 2013; Accepted September 24, 2014

DOI: $10.3892 / \mathrm{mmr} .2014 .2923$

\begin{abstract}
In the present study, a human transforming growth factor- $\beta 1$ (TGF- $\beta 1$ ) small interfering RNA (siRNA) plasmid vector (TGF- $\beta 1$-siRNA) was constructed to investigate its effects on the proliferation and differentiation of human lung fibroblasts in vitro and its interference effects on radiation-induced lung injury in vivo. Reverse transcription quantitative polymerase chain reaction and enzyme linked immunosorbent assay revealed that the mRNA and protein expression of TGF- $\beta 1$ in the HFL-I cells were inhibited by TGF- $\beta 1$-siRNA and flow cytometry demonstrated a significant increase in apoptosis of the HFL-I cells. Adult, female, specific-pathogen-free C57BL/6 mice were used in the in vivo animal investigations and were randomly divided into the four following groups: control without any treatment, radiation alone, radiation followed by empty vector transfection and radiation followed by TGF- $\beta 1$-siRNA vector transfection. Hematoxylin and eosin and Van-Gieson staining revealed that certain radiation-induced histopathological changes of the lung, including inflammation, edema, the density of surface pulmonary interstitial collagen fibers in the alveolar septum, TGF- $\beta 1$-positive reactions in alveolar epithelial cells and pulmonary interstitial macrophages were less marked in the mice transfected with TGF- $\beta 1$-siRNA compared with the mice without transfection or those transfected with empty vectors. The serum levels of TGF- $\beta 1$ levels in
\end{abstract}

Correspondence to: Dr Meizhen Wan or Dr Judong Luo, Department of Radiotherapy, Changzhou Tumor Hospital, Soochow University, 1 Huaide Road, Changzhou, Jiangsu 213001, P.R. China

E-mail: czwmz2008@163.com

E-mail: judongluo@aliyun.com

*Contributed equally

Key words: transforming growth factor- $\beta 1$, small interfering RNA, human embryonic lung fibroblast, radiation, lung injury the irradiated mice increased significantly at four weeks and peaked at eight weeks after radiation, compared with the control. Serum levels of TGF- $\beta 1$ in the irradiated mice transfected with TGF- $\beta 1$-siRNA also increased gradually and a significant difference was observed compared with those irradiated without transfection. The mRNA expression levels of TGF- $\beta 1$ in the mice transfected with TGF- $\beta 1$-siRNA were markedly lower compared with those of the other radiation groups. The present study suggested that the TGF- $\beta 1$-siRNA vector reduced the activity of TGF- $\beta 1$ by downregulating the mRNA expression of TGF- $\beta 1$ and thereby effectively suppressing inflammatory reactions and defending against radiation-induced lung injury.

\section{Introduction}

Radiation-induced lung injury typically presents with two distinct subsequent clinical phases, interstitial pneumonia and fibrosis, which frequently occur following completion of radiation therapy for thoracic neoplasia. This complex process is regulated by mutually dependent cellular lineages and a multitude of biologically active molecules. Transforming growth factor- $\beta 1$ (TGF- $\beta 1$ ) is an important growth factor among the molecules that are expressed in tissues following radiation exposure and a positive correlation has been observed between the severity of radiation-induced lung injury and TGF- $\beta 1$ signal activation $(1,2)$. Lung fibroblasts are one of the main cells in which TGF- $\beta 1$ is highly expressed, thus injury may be prevented by inhibiting the expression of TGF- $\beta 1$. Since its identification by Fire et al (3), RNA interference (RNAi) has been used to guide sequence-specific gene silencing of target mRNAs.

In the present study, the RNAi strategy was used to downregulate TGF- $\beta 1$ by constructing a small interfering RNA (siRNA) plasmid vector, termed TGF- $\beta 1$-siRNA. The effects of TGF- $\beta 1$-siRNA on the proliferation and differentiation of lung fibroblast, HFL-I, cells the intervention effects of the expression vector on the radiation-induced lung injury were then investigated. The aim of the present study was to identify effective treatment options to assist in the prevention and/or management of radiation-induced lung injury. 


\section{Materials and methods}

Construction of the TGF- $\beta 1$-siRNA expression vector. According to Reynolds et al (4), three synthetic siRNAs targeting human TGF- $\beta 1$ mRNA (GenBank accession no. NM000660), with a length of 19-21 nucleotides, were synthesized by GenePharma Co., Ltd. (Shanghai, China), of which one effective siRNA sequence (5'-GCAGAGTACACA CAGCATA-3') was adopted for the subsequent experiments.

\section{In vitro experiment}

Cell culture and shRNA transfection. The human embryonic lung fibroblast, HFL-I, was obtained from the cell bank of the Chinese Academy of Sciences (Shanghai, China), and were maintained in F12K supplemented with $10 \%$ fetal bovine serum and antibiotics $(100 \mathrm{U} / \mathrm{ml}$ penicillin $\mathrm{G}$ and $100 \mathrm{U} / \mathrm{ml}$ streptomycin sulfate; Gibco, Grand Island, NY, USA) at $37^{\circ} \mathrm{C}$ in $5 \% \mathrm{CO}_{2}$. HFL-I cells were resuspended using $1 \mathrm{ml}$ trypsin, and plated in six-well plates at a density of $1.2 \times 10^{5}$ cells/well. After a period of $24 \mathrm{~h}$, the siRNA duplexes were mixed with Lipofectamine 2000 (Invitrogen Life Technologies, Carlsbad, CA, USA) in Opti-MEM ${ }^{\circledR}$ I reduced serum medium for $20 \mathrm{~min}$ at room temperature to enable complex formation. The total volume $(250 \mu \mathrm{l})$ of transfection mixture was then added to the six-well plates, which were randomly divided into the positive interference group, which was transfected with TGF- $\beta 1$-siRNA, the negative control group, which was transfected with empty vectors and the blank control group without transfection. Following $6 \mathrm{~h}$ incubation, the medium was replaced by $4 \mathrm{ml}$ Opti-MEM ${ }^{\circledR}$ I containing $5 \%$ fetal bovine serum and the cells were incubated for another $42 \mathrm{~h}$ prior to harvesting for reverse transcription quantitative PCR (RT-qPCR) analysis.

$R T$ - $q P C R$. The total RNA was isolated from $1 \times 10^{6}$ cells of each well using TRIzol ${ }^{\circledR}$ reagent (Invitrogen Life Technologies). Total RNA ( $1 \mu \mathrm{g})$ was reverse-transcribed into cDNA using AMV Reverse Transcriptase (Promega, Madison, WI, USA). Oligonucleotide primers were designed for the specific amplification of TGF- $\beta 1$ and the internal control $\beta$-actin according to the sequences published in GenBank (Table I). Amplifications were performed using the FTC-2000 (Funglyn Biotech, Inc., Toronto, ON, Canada) sequence detection system, using SYBR-Green I (ShineGene, Shanghai, China). The thermal profile was as follows: $94^{\circ} \mathrm{C}$ for $4 \mathrm{~min}$ followed by 35 cycles of $94^{\circ} \mathrm{C}$ for $20 \mathrm{sec}, 60^{\circ} \mathrm{C}$ for $30 \mathrm{sec}$ and $72^{\circ} \mathrm{C}$ for $30 \mathrm{sec}$. The TGF- $\beta 1$ mRNA level in each sample, relative to that of $\beta$-actin mRNA, was calculated using the $2^{-\Delta \Delta \mathrm{Ct}}$ formula. The levels of $\beta$-actin were not changed in any of the experimental conditions (Table I).

Enzyme linked immunosorbent assay (ELISA). The supernatant of the cultured cells was collected $48 \mathrm{~h}$ after transfection and the concentrations of TGF- $\beta 1$ were measured using an ELISA kit (R\&D Systems, Inc., Minneapolis, MN, USA) according to the manufacturer's instructions. The standard immunoreagent was diluted with sample dilution to $31.2,62.5$, $125,250,500,1,000$ and 2,000 $\mathrm{ng} / \mathrm{ml}$ as a series multiproportion dilution. The absorbance values were determined at $450 \mathrm{~nm}$ using a Bio-Rad Model 450 microplate reader (Bio-Rad, Hercules, CA, USA) and a standard curve was established to calculate the concentrations of TGF- $\beta 1$ accordingly.
Table I. Nucleotide sequences of primers used for quantitative polymerase chain reaction and product sizes.

\begin{tabular}{llc}
\hline Gene & \multicolumn{1}{c}{$\begin{array}{c}\text { Primer sequence } \\
\left(5^{\prime}-3^{\prime}\right)\end{array}$} & $\begin{array}{c}\text { Amplicon } \\
\text { size (bp) }\end{array}$ \\
\hline$\beta$-actin & $\begin{array}{c}\text { AGCACAGAGCCTCGCCTTT } \\
\text { AGGGTGAGGATGCCTCTCTT }\end{array}$ & 258 \\
TGF- $\beta 1$ & GTACCTGAACCCGTGTTGCT & 486 \\
& GTCCTTGCGGAAGTCAATGT & \\
\hline
\end{tabular}

TGF- $\beta 1$, transforming growth factor- $\beta 1$.

Annexin V apoptosis detection assay. The HFL-I cells were plated onto 6-well plates at a density of $4 \times 10^{5} /$ well and randomly divided into the positive interference group (transfected with TGF- $\beta 1$-siRNA), negative control group (transfected with empty vectors) and control group (without transfection), with two replicates in each. Following incubation of the cells for $72 \mathrm{~h}$, apoptosis was analyzed using a BD FACSAria flow cytometer (BD Biosciences, San Jose, CA, USA), using a fluorescein isothiocyanate (FITC) Annexin V/Dead Cell Apoptosis kit with FITC Annexin V and propidium iodide (Invitrogen Life Technologies).

\section{In vivo experiment}

Animals and experimental design. In total, 384 adult, female, specific-pathogen-free C57BL/6 mice ( $~ 8$ weeks old), were purchased from Vital River Laboratory (Beijing, China). The mice were maintained in a cage, each containing between four and six mice, supplied with standard laboratory food and water. The mice were randomly divided into the following four groups: control without any treatment ( 24 mice), radiation alone (120 mice); radiation followed by transfection with empty vectors (120 mice) and radiation followed by transfection with the TGF- $\beta 1$-siRNA vector (120 mice). The empty vectors and TGF- $\beta 1$-siRNA vectors were transfected into the lung of the mice in the transfection groups, respectively, on days $1,7,14$, 28 and 60 of radiation ( 24 mice/time point). The present study was performed in strict accordance with the recommendations in the Guide for the Care and Use of Laboratory Animals of the National Institutes of Health and the animal experimental procedures were approved by the Institutional Animal Care and Use Committee of Suzhou University (Suzhou, China).

The mice were restrained on the treatment table with specific jigs and a $23 \mathrm{~mm}$ thick paraffin block was placed above the thoraces of the animal to obtain an even distribution of radiation dose, using lead shields for radiation protection of the head and abdomen. A dose of 12 Gy to the entire thorax was delivered in a single fraction at the anterior field using a linear accelerator (Primus; Siemens AG, Munich, Germany). The radiation parameters were a beam energy of $6 \mathrm{MV}$, an X-ray source-surface distance of $100 \mathrm{~cm}$ and a field size of $10 \mathrm{~cm}^{2}$ to provide adequate coverage of the entire lung.

The irradiated mice were then anesthetized using $3.8 \%$ chloral hydrate $(10 \mathrm{ml} / \mathrm{kg})$ and fixed upright prior to injection with the specific TGF- $\beta 1$-siRNA vector or empty vector $\left(10^{9} \mathrm{pfu} / 0.11 \mathrm{ml}\right)$. 


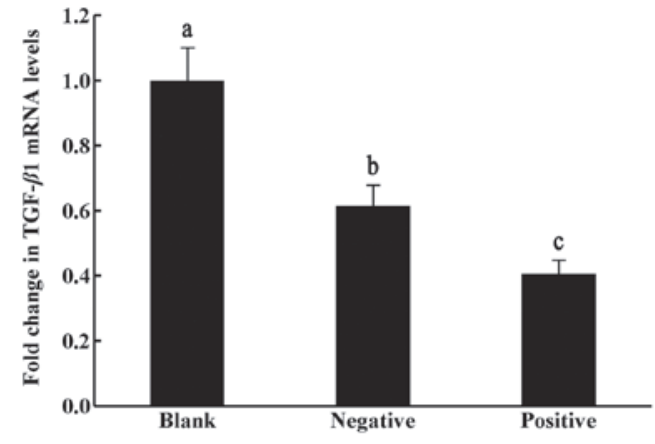

Figure 1. mRNA expression of TGF- $\beta 1$ in HFL-I cells of the blank control group (no transfection), negative control group (transfected with empty vectors) and positive interference group (transfected with TGF- $\beta 1$-small interfering RNA). Data are expressed as changes relative to the blank control group. Data are expressed as the mean \pm standard deviation. a,b,c Statistically significant differences according to analysis of variance $(\mathrm{P}<0.05)$. TGF- $\beta 1$, transforming growth factor- $\beta 1$

Sampling. A total of three mice from each group were sampled at days 2, 15 and 28 and at week 8,12, 16, 20 and 24 of transfection. Initially, $2 \mathrm{ml}$ blood was obtained immediately from the heart and placed into an anticoagulant tube containing ethylenediaminetetraacetic acid (BD Biosciences). Following standing for $30 \mathrm{~min}$ and centrifugation at $1,500 \mathrm{x} \mathrm{g}$ for $15 \mathrm{~min}$, the serum was frozen at $-70^{\circ} \mathrm{C}$. The hilum of the left lung was then ligated and $4 \mathrm{ml}$ physiological saline was injected following endotracheal intubation. This was then removed by suction following standing for $3 \mathrm{~min}$ standing and was repeated three times. Bronchoalveolar lavage fluid was collected and centrifuged at 3,000 $\mathrm{x}$ g for $4 \mathrm{~min}$ and the supernate was then stored at $-70^{\circ} \mathrm{C}$. The left lung was fixed in $10 \%$ formaldehyde solution (Sinopharm Chemical Reagent Co., Ltd., Shanghai, China) for $24 \mathrm{~h}$, dehydrated, embedded in paraffin (Sinopharm Chemical Reagent Co., Ltd.) and sectioned on a microtome (Leica, Wetzlar, Germany). The sections were then stained with hematoxylin and eosin (H\&E) and Van-Gieson (VG) (Zhongshan Golden Bridge Bio-technology, Beijing, China) for the observation of pulmonary fibrosis. In addition, the right lung was stored in liquid nitrogen.

Immunohistochemistry. Slides were deparaffinized, rehydrated though a graded series of ethanol and treated with $3 \% \mathrm{H}_{2} \mathrm{O}_{2}$ in $\mathrm{H}_{2} \mathrm{O}$ to quench endogenous peroxidase activity. The specimens were incubated overnight at $4^{\circ} \mathrm{C}$ with rabbit polyclonal antibody against mouse TGF- $\beta 1$ (1:100; Santa Cruz Biotechnology, Inc., Santa Cruz, CA, USA) using the ULtraSensitive $^{\text {TM }}$ S-P Mouse kit-9701 and was detected with diaminobenzidine staining (Fuzhou Maixin Biotechnology Co., Ltd., Fuzhou, China) used as chromogen. Subsequently, 10 randomly selected fields on each slide were observed and images were captured using an Olympus BX51 microscope image acquisition system (Olympus, Tokyo, Japan). The pulmonary interstitial surface density and integral optical density were quantified using Image-Pro Plus 6.0 software (Media Cybernetics, Silver Spring, MD, USA) and deposition of collagen in the lung tissue was observed by VG staining.

ELISA. The levels of TGF- $\beta 1$ in the serum and the bronchoalveolar lavage fluid were determined using ELISA kits (R\&D Systems, Minneapolis, MN, USA) according to the manufacturer's instructions.
Statistical analysis. Data are expressed as the mean \pm standard deviation. The differences between any two groups were determined by analysis of variance. $\mathrm{P}<0.05$ was considered to indicate a statistically significant difference.

\section{Results}

Effects of TGF- $\beta 1$-siRNA on human embryonic lung fibroblast HFL-I cells in vitro

TGF- $\beta 1$ mRNA levels in HFL-I cells quantified by RT-qPCR. The relative ratios of mRNA expression of TGF- $\beta 1$ between the blank control with no transfection, the negative control transfected with empty vectors and the positive interference group transfected with TGF- $\beta 1$-siRNA, were significantly different $(\mathrm{P}<0.05)$. The expression levels of the target gene TGF- $\beta 1$ were lowest in the TGF- $\beta 1$-siRNA injection group, suggesting that the constructed interference plasmid exerted interference effects (Fig. 1).

$T G F-\beta 1$ protein contents in the cell culture medium measured by ELISA. The contents of TGF- $\beta 1$ measured in the blank control, negative control and positive interference groups were $33.8 \pm 3.8,32.3 \pm 2.4$ and $24.0 \pm 3.0 \mathrm{ng} / \mathrm{ml}$, respectively. The levels of TGF- $\beta 1$ were lowest in the positive interference group, which differed significantly from those of the other groups $(\mathrm{P}<0.05$; Fig. 2$)$.

Effect of TGF- $\beta 1$-siRNA on the apoptosis of HFL-I cells measured by Annexin $V$. Following transfection for $72 \mathrm{~h}$, the apoptotic rate of the HFL-I cells in the positive interference group (78\%) was significantly higher compared with those of the negative and blank control groups (51 and 52\% respectively; $\mathrm{P}<0.05$ ), while no significant differences were observed between the negative control and the blank control groups (Fig. 3).

\section{Effects of TGF- $\beta 1$-siRNA on radiation-induced lung injury} in vivo.

General conditions of the experimental mice. All the mice were weighed every 2 weeks following radiation, which were between 19 and $25 \mathrm{~g}$. The mice were in good condition with normal tail-lift reflection and no hair loss, skin edema or rupture was observed in the irradiated area. The respiratory frequencies of the irradiated mice without transfection increased significantly to $165 \pm 13$ breaths/min $(20 \%)$ in the eighth week, compared with the control group without any treatment and the result was similar in the irradiated mice transfected with empty vectors. In the mice transfected with TGF- $\beta 1$-siRNA, the respiratory frequencies increased significantly from the 1st day of radiation to $125 \pm 5$ breaths/min $(\sim 20 \%)$ in the 10th week $(\mathrm{P}<0.01)$, compared with the control and no dyspnea observed (Fig. 4).

Histopathological changes of the lung. Normal lung morphology was observed in the control mice following H\&E staining. In the irradiated mice without transfection, thickened alveolar walls, hemangiectasis, hyperemia of the pulmonary capillaries and a low level of inflammatory cell infiltration were observed on the second day of radiation. Focal inflammatory infiltration was observed from day 15 onward and pulmonary edema with local pulmonary consolidation became more marked in the week 8 and 12 of radiation (Fig. 5A-D). The levels of inflammation and edema 


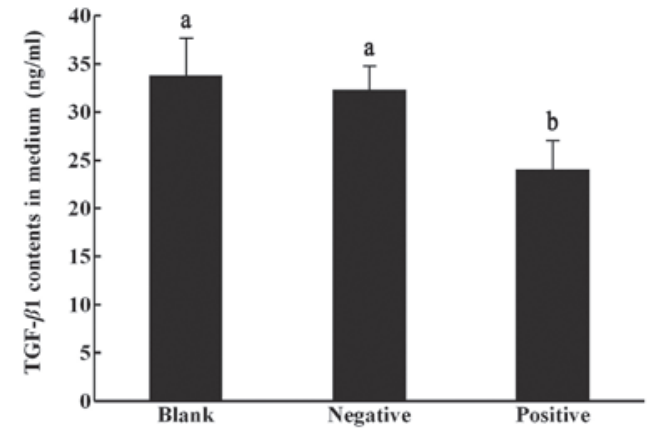

Figure 2. TGF- $\beta 1$ protein in the HFL-I cell culture medium of the blank control group (without transfection), negative control group (transfected with empty vectors) and positive interference group (transfected with TGF- $\beta 1$-small interfering RNA). Data are expressed as the mean \pm standard deviation. ${ }^{\mathrm{a}, \mathrm{b}, \mathrm{c}, \mathrm{S}}$ Statistically significant differences according to analysis of variance $(\mathrm{P}<0.05)$. TGF- $\beta 1$, transforming growth factor- $\beta 1$.

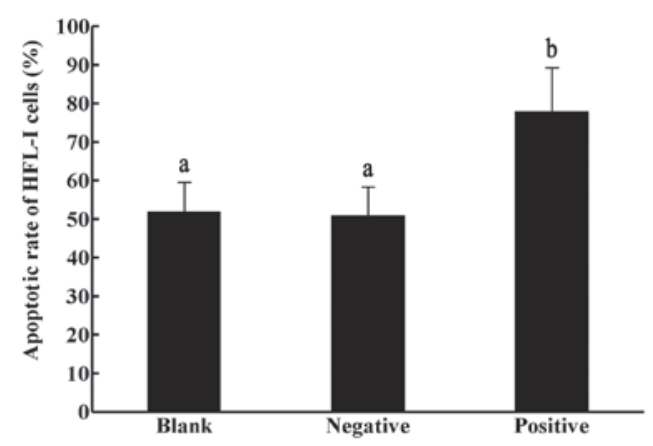

Figure 3. Apoptotic rate of HFL-I cells in the blank control group (without transfection), negative control group (transfected with empty vectors) and the positive interference group (transfected with transforming growth factor- $\beta 1$-small interference RNA). Data are expressed as the mean \pm standard deviation. a,b,c Statistically significant differences according to analysis of variance $(\mathrm{P}<0.05)$.

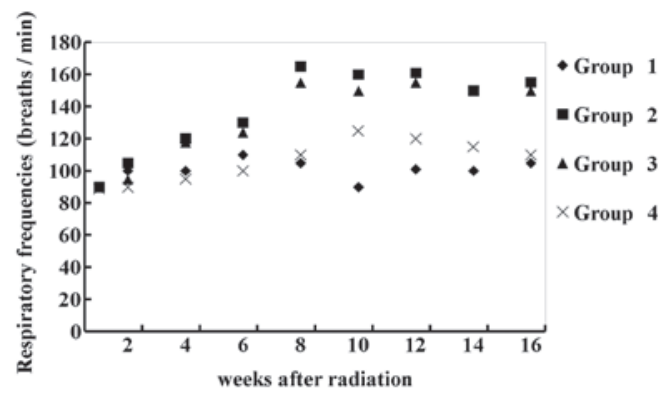

Figure 4. Changes in respiratory frequencies over time in control mice without any treatment, irradiated mice without transfection, irradiated mice transfected with empty vectors and irradiated mice transfected with transforming growth factor- $\beta 1$-small interfering RNA vectors (designated group 1,2,3 and 4, respectively).

were less marked in the mice transfected with TGF- $\beta 1$-siRNA on the first day of radiation (Fig. 5E-H). Compared with that of the control without any treatment, the surface density of pulmonary interstitial collagen fibres in mice without transfection and mice transfected with empty vectors increased gradually in the 4 th and 8 th weeks of radiation $(\mathrm{P}<0.05)$, which was significantly reduced in the TGF- $\beta 1$-siRNA transfection group $(\mathrm{P}<0.05$; Table II). The VG staining revealed that the dunkelrosa collagens in mice transfected with TGF- $\beta 1$-siRNA, distributed mainly in the airway and vascular adventitia, were reduced compared with those in the irradiated mice without transfection on the 2 nd and 15th days of radiation. From the 4th week of radiation onwards, collagen fibers in the vascular adventitia and the alveolar septum were increased in mice without transfection, which was allayed to some extent in the TGF- $\beta 1$-siRNA transfected mice (Fig. 5I-K). Furthermore, compared with mice transfected with TGF- $\beta 1$-siRNA at the later phases of radiation (28th day; Fig. 5J), fewer collagen fibers were observed in the vascular adventitia and the alveolar septum in mice transfected with TGF- $\beta 1$-siRNA earlier (7th day; Fig. 5I).

Immunohistochemistry. Few areas of TGF- $\beta 1$ positive reaction were detected in the alveolar septum, fine bronchial smooth muscle, vascular smooth muscle, endothelium and vascular surroundings of the control lung tissue, suggesting that the expression of TGF- $\beta 1$ is normally weak or absent. In the irradiated mice without transfection, radiation for 4 and 8 weeks significantly enhanced the expression of TGF- $\beta 1$ in the above-mentioned regions and, in particular, high levels of expression were found in the alveolar epithelial cells and pulmonary interstitial macrophages. Compared with this group, the positive area in the TGF- $\beta 1$-siRNA transfected mice was markedly decreased $(\mathrm{P}<0.05$; Table II).

Levels of TGF- $\beta 1$ in the serum and bronchoalveolar lavage fluid measured by ELISA. Changes in the levels of TGF- $\beta 1$ in the serum and bronchoalveolar lavage fluid were almost in accordance with the histopathological changes observed in the lung tissues. Specifically, the levels of TGF- $\beta 1$ in the serum of irradiated mice without transfection increased with time, which increased significantly 4 weeks and peaked 8 weeks after radiation, compared with the control $(\mathrm{P}<0.05)$. The levels of TGF- $\beta 1$ in the serum of irradiated mice transfected with TGF- $\beta 1$-siRNA also increased gradually, however it differed significantly compared with that in the mice irradiated without transfection $(\mathrm{P}<0.05)$. Changes in the levels of TGF- $\beta 1$ in the bronchoalveolar lavage fluid were similar with that in the serum, however, a reduction was observed following the peak in the fourth week of radiation (Table III).

Changes in mRNA expression levels of TGF- $\beta 1$ quantified by $R T-q P C R$. Following radiation, the mRNA expression of TGF- $\beta 1$ was significantly upregulated in mice without any transfection and in those transfected with empty vectors, compared with the control $(\mathrm{P}<0.05)$. In general, the mRNA expression levels of TGF- $\beta 1$ in mice transfected with TGF- $\beta 1$-siRNA were markedly lower compared with those in the mice without transfection or in those transfected with empty vectors. This difference was significant in the fourth, eighth, 12th and 16th week of radiation $(\mathrm{P}<0.05)$. The mRNA expression of TGF- $\beta 1$ was upregulated from the 8th week of radiation, peaked at the 12th week and was then downregulated. Notably, in the 12th week of radiation, the mRNA expression levels of TGF- $\beta 1$ were highest in the radiated non-transfection group, followed by the TGF- $\beta 1$-siRNA transfection group and then the controls (Fig. 6). Furthermore, the mRNA expression levels of TGF- $\beta 1$ were lower in mice transfected with TGF- $\beta 1$-siRNA (Fig.7A) on the first day following radiation compared with those transfected with TGF- $\beta 1$-siRNA at later phases of radiation (28th day; Fig. 7B). 
Table II. Variations in the surface density of pulmonary interstitial collagen fibers and the TGF- $\beta 1$ staining intensity positive for radiation-induced lung injury.

\begin{tabular}{|c|c|c|c|c|c|c|c|c|c|c|}
\hline \multirow[b]{2}{*}{ Group } & \multicolumn{5}{|c|}{ Surface density of pulmonary interstitial collagen fibers $(\%)^{\mathrm{a}}$} & \multicolumn{5}{|c|}{ TGF- $\beta 1$ staining intensity of positive reaction $(\%)^{\mathrm{b}}$} \\
\hline & 2nd day & 15 th day & 4th week & 8th week & 12 th week & 2nd day & 15 th day & 4 th week & 8th week & 12th week \\
\hline 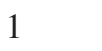 & 13 & & & & & & & & & \\
\hline 2 & $36.2 \pm 13.1$ & $43.4 \pm 8.1$ & $51.3 \pm 3.4$ & $54.1 \pm 8.4$ & $73.9 \pm$ & $0.52 \pm 0.3$ & $0.53 \pm 0.3$ & $0.79 \pm 0.5$ & $0.80 \pm 0.5$ & $0.83 \pm 0.3$ \\
\hline 3 & $33.2 \pm 3.1$ & $42.2 \pm 1.7$ & $46.3 \pm 5.1$ & $56.6 \pm 3.4$ & $66.2 \pm 8.5$ & $0.53 \pm 0.2$ & $0.52 \pm 0.2$ & $0.72 \pm 0.3$ & $0.82 \pm 0.3$ & $0.82 \pm 0.5$ \\
\hline 4 & $25.5 \pm 7.5$ & $21.5 \pm 8.6$ & $23.6 \pm 5.6$ & $21.8 \pm 5.2$ & $21.0 \pm 9.7$ & $0.29 \pm 0.15$ & $0.29 \pm 0.3$ & $0.19 \pm 0.2$ & $0.26 \pm 0.2$ & $0.22 \pm 0.3$ \\
\hline
\end{tabular}

${ }^{\mathrm{a}}$ Group 1 vs. group $2(\mathrm{P}<0.001)$; group 1 vs. group $3(\mathrm{P}=0.0082)$; group 1 vs. group $4(\mathrm{P}=0.001)$; group 2 vs. group 3 ( $\left.\mathrm{P}=0.21\right)$; group 2 vs. group $4(\mathrm{P}=0.002)$; group 3 vs. group $4(\mathrm{P}=0.001)$. ${ }^{\mathrm{b}} \mathrm{Group} 1$ vs. group $2(\mathrm{P}<0.001)$; group 1 vs. group $3(\mathrm{P}<0.001)$; group 1 vs. group $4(\mathrm{P}=0.007)$; group 2 vs. group $3(\mathrm{P}=0.41)$; group 2 vs. group $4(\mathrm{P}=0.001)$; group 3 vs. group $4(\mathrm{P}=0.002)$. Group 1, control mice without any treatment; group 2, radiated mice without transfection; group 3, radiated mice transfected with empty vectors; group 4, radiated mice transfected with the TGF- $\beta 1$-small interfering RNA vector. TGF- $\beta 1$, transforming growth factor- $\beta 1$.
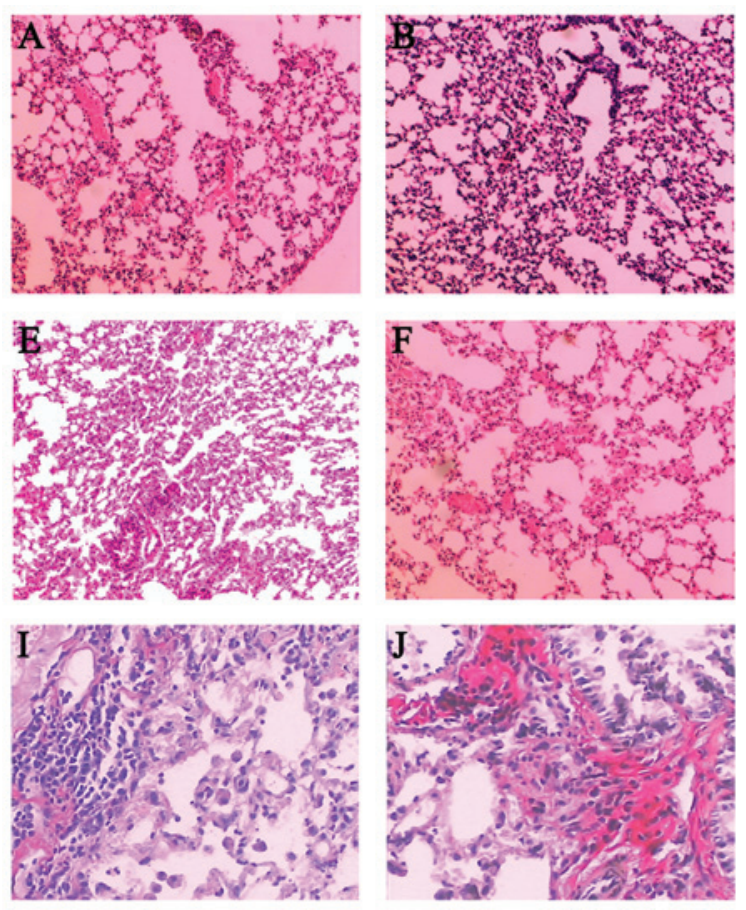
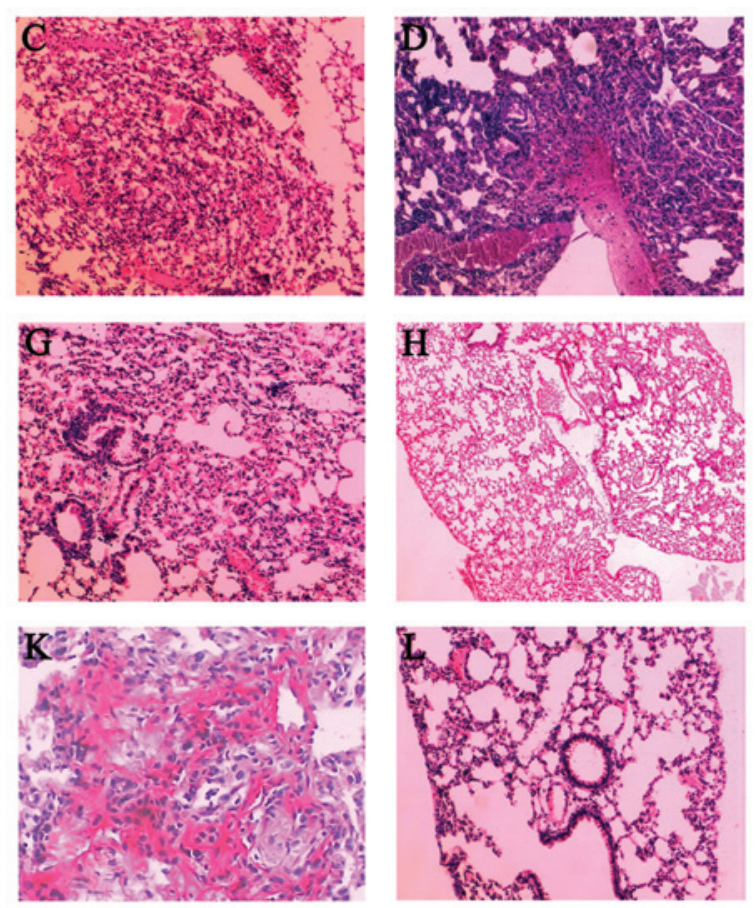

Figure 5. Histopathological changes of the lung tissues of mice in different treatment groups. (A) On the second day of radiation, hyperaemia and edema were observed in the irradiated mice without transfection. (B) On the 15 th day of radiation, inflammation was exacerbated in the irradiated mice without transfection. (C) At the eighth week of radiation, thickened alveolar walls and diminished alveolar space were observed in the irradiated mice without transfection. (D) At the 12th week of radiation, pulmonary fibrosis was observed in the irradiated mice without transfection. (E) On the second day of transfection, edema of alveolus pulmonis and a low level of inflammatory cell infiltration were observed in the mice transfected with TGF- $\beta 1$-siRNA on the first day of radiation. (F) On the 15th day of transfection, hyperaemia and edema were observed in the mice transfected with TGF- $\beta 1$-siRNA on the first day of radiation; (G) At the fourth week of transfection, thickened alveolar walls and diminished alveolar space were observed in the mice transfected with TGF- $\beta 1$-siRNA on the first day of radiation; $(\mathrm{H})$ At the 12th week of transfection, the injured lung tissue recovered in the mice transfected with TGF- $\beta 1$-siRNA on the first day of radiation. (I) At the fourth week of transfection, fewer collagenous fibers in the vascular adventitia and alveolar septum were observed in the mice transfected with TGF- $\beta 1$-siRNA on the seventh day of radiation. (J) At the fourth week of transfection, collagenous fibers in the vascular adventitia and alveolar septum formed in the mice transfected with TGF- $\beta 1$-siRNA on the 28th day of radiation. (K) On the fourth week of radiation, collagenous fibers in the vascular adventitia and alveolar septum were increased in the mice without transfection. (L) Normal lung tissue. TGF- $\beta 1$-siRNA, transforming growth factor- $\beta 1$-small interfering RNA.

\section{Discussion}

Radiation-induced lung injury is one of the most common complications following thoracic radiochemotherapy, of which radiation pneumonitis and pulmonary fibrosis represent acute and late phases, respectively. It can markedly decrease the quality of life and even the life span of patients with a thoracic tumor. This injury may be induced by various factors, involving the injured cells targeted by radiation and profibrotic cytokines produced by damaged and activated cells (5). In the later phases, cytokine-mediated proliferation, activation and differentiation of fibroblasts into myofibroblasts occur with 
Table III. Changes in the levels of TGF- $\beta 1$ in the serum and bronchoalveolar lavage fluid (ng/ml).

\begin{tabular}{|c|c|c|c|c|c|c|c|c|c|c|}
\hline \multirow[b]{2}{*}{ Group } & \multicolumn{5}{|c|}{ Serum TGF- $\beta 1^{\mathrm{a}}$} & \multicolumn{5}{|c|}{ Bronchoalveolar lavage fluid TGF- $\beta 1^{\mathrm{b}}$} \\
\hline & 2nd day & 15th day & 4th week & 8th week & 12th week & 2nd day & 15 th day & 4th week & 8th week & 12th week \\
\hline 1 & $3.68 \pm 0.96$ & $3.68 \pm 0.96$ & $3.68 \pm 0.96$ & $3.68 \pm 0.96$ & $3.68 \pm 0.96$ & $3.41 \pm 0.89$ & $3.41 \pm 0.89$ & $3.41 \pm 0.89$ & $3.41 \pm 0.89$ & $3.41 \pm 0.89$ \\
\hline 2 & $14.74 \pm 2.16$ & $24.94 \pm 2.16$ & $29.32 \pm 3.20$ & $42.14 \pm 3.78$ & $38.63 \pm 4.94$ & $4.98 \pm 1.12$ & $10.40 \pm 1.21$ & $9.85 \pm 2.11$ & $9.99 \pm 1.02$ & $8.44 \pm 2.23$ \\
\hline 3 & $14.2 \pm 3.1$ & $24.2 \pm 2.73$ & $26.31 \pm 5.12$ & $41.60 \pm 3.47$ & $34.24 \pm 8.58$ & $4.78 \pm 2.32$ & $10.98 \pm 1.92$ & $9.98 \pm 3.12$ & $8.98 \pm 2.32$ & $7.18 \pm 1.64$ \\
\hline 4 & $9.85 \pm 1.58$ & $13.86 \pm 1.14$ & $24.68 \pm 2.18$ & $35.61 \pm 2.55$ & $33.59 \pm 3.43$ & $3.64 \pm 1.35$ & $5.87 \pm 2.31$ & $4.44 \pm 2.54$ & $4.82 \pm 1.26$ & $3.94 \pm 2.41$ \\
\hline
\end{tabular}

${ }^{\mathrm{a}}$ Group 1 vs. group $2(\mathrm{P}<0.001)$, group 1 vs. group $3(\mathrm{P}<0.001)$, group 1 vs. group $4(\mathrm{P}<0.001)$, group 2 vs. group 3 ( $\left.\mathrm{P}=0.21\right)$, group 2 vs. group 4 $(\mathrm{P}=0.002)$, group 3 vs. group $4(\mathrm{P}=0.002)$; ${ }^{\mathrm{b}} \mathrm{Group} 1$ vs. group $2(\mathrm{P}=0.001)$, group 1 vs. group $3(\mathrm{P}=0.002)$, group 1 vs. group 4 ( $\left.\mathrm{P}=0.001\right)$, group 2 vs. group $3(\mathrm{P}=0.111)$, group 2 vs. group $4(\mathrm{P}=0.003)$, group 3 vs. group $4(\mathrm{P}=0.002)$. Group 1 , control mice with no treatment; group 2 , irradiated mice without transfection; group 3 , irradiated mice transfected with empty vectors; group 4, irradiated mice transfected with the TGF- $\beta 1$-small interfering RNA vectors. TGF- $\beta 1$, transforming growth factor- $\beta 1$.

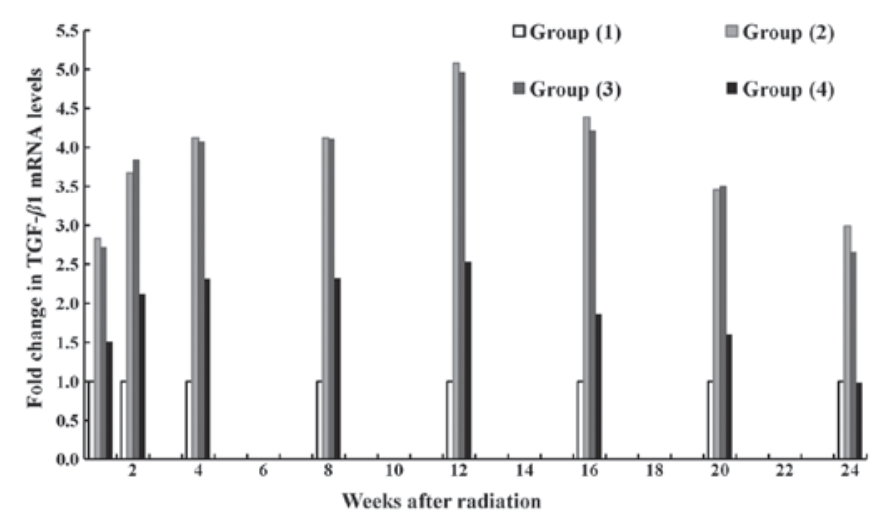

Figure 6. Changes in the mRNA expression of TGF- $\beta 1$ in control mice without any treatment, irradiated mice without transfection, irradiated mice transfected with empty vectors and irradiated mice transfected with TGF- $\beta 1$-small interfering RNA vectors (groups 1, 2, 3 and 4, respectively). Data are expressed as changes relative to the blank control group sampled at the same time-point. TGF- $\beta 1$, transforming growth factor- $\beta 1$.

associated collagen deposition, which may cause respiratory failure. Currently, several pharmaceuticals are used in the management of radiation pneumonitis in the early phase, including glucocorticoids, non-steroidal anti-inflammatory drugs, adjuvant interferon $\mathrm{R}$ and other drugs, which relieve lung injury. However, the formation of a mass of pulmonary fibrosis remains possible in the late phase.

Previous investigations have demonstrated that between a few hours and a few days following radiation, quantities of growth factors are synthesized and secreted, which continues for several months. These early changes have profound impacts on pathological and physiological changes in the late phase. Cytokines including TGF- $\beta 1$, platelet-derived growth factor (PDGF), tumor necrosis factor- $\alpha$ (TNF- $\alpha)$, interleukin-1 (IL-1) and insulin-like growth factor-1 are involved in pulmonary fibrosis, by which multi-cellular interactions are mediated to initiate and maintain the process of fibrosis. TGF- $\beta 1$, one of the factors regulating the growth of various human epithelial cells, has a wide range of biological effects on cell growth, differentiation, extracellular matrix deposition and immune response (6). TGF- $\beta 1$ is considered to be closely associated with the formulation and maintenance
A

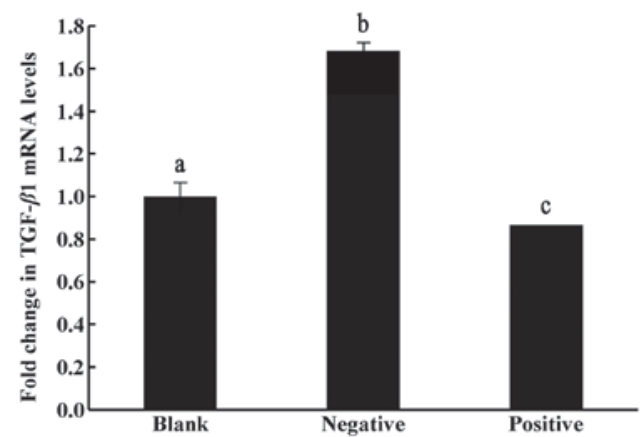

B

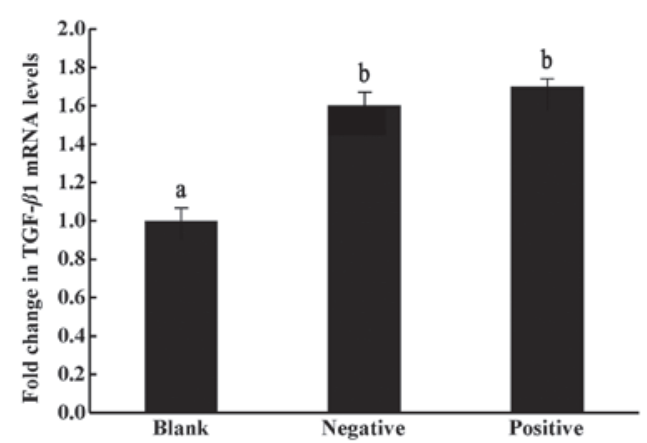

Figure 7. mRNA expression of TGF- $\beta 1$ in the lung tissue of irradiated mice transfected with TGF- $\beta 1$-siRNA at different time points. (A) Mice transfected one day after radiation for one day. (B) Mice transfected four weeks after radiation for 28 days. Data are expressed as the change relative to the blank control group at the same time point and are expressed as the mean \pm standard deviation. ${ }^{\text {a,b,c }}$ Statistically significant differences according to analysis of variance $(\mathrm{P}<0.05)$. Blank, control mice with no treatment; negative, radiated mice transfected with empty vectors; positive, radiated mice transfected with TGF- $\beta 1$-siRNA vectors. TGF- $\beta 1$-siRNA, transforming growth factor- $\beta 1$-small interfering RNA.

of radiation pulmonary fibrosis, since increased levels of TGF- $\beta 1$ are detected in pulmonary fibrosis induced by bleomycin, cyclophosphamide and radiation (7-10). TGF- $\beta 1$ stimulates the synthesis of IL-1, TNF- $\alpha$ and PDGF by inflammatory cells or fibroblast, suggesting the importance of this factor in the cytokine network, while its own production also exists in an autocrine manner. TGF- $\beta 1$ is also responsible for the regulation of extracellular matrix (ECM) by two different mechanisms (2). It enhances ECM synthesis by inducing the 
synthesis of collagen and various other extracellular matrix components, including fibronectin and it can reduce ECM degradation, partially by inhibiting the expression of proteolytic enzyme. Chiang et al (11) reported that in mice receiving radiation, pulmonary fibrosis or subacute radiation pneumonia develops and TGF- $\beta 1$ is upregulated, particularly in the late phases of pulmonary fibrosis.

Understanding the molecular mechanisms and signaling pathways of radiation-induced lung injury make it possible to intervene and prevent this injury by using certain biological techniques similar to anticytokine therapy, which has been utilized as a novel treatment to inhibit pulmonary fibrosis. Considering the important roles of TGF- $\beta 1$ in the development of fibrosis induced by radiation, matrix generation may be inhibited and matrix degradation may be stimulated by suppressing the activity of TGF- $\beta 1$ in antifibrotic therapy. As RNAi relies on the sequence-specific interaction between siRNAs and mRNA, siRNAs can be tailored to silence almost any gene. It is one of the important mechanisms in post-transcriptional gene silencing in eukaryotes. The central process of RNAi is the cleavage of dsRNA into smaller fragments of a defined length ( 21-23 nucleotides) by the enzyme Dicer. RNAi has been widely used for the analysis of gene function and signal transduction, representing a potentially promising approach for gene therapy. It has been reported that the inhibitory effect of siRNA synthesized via a plasmid or viral vector on the target gene is similar with that of synthetic siRNA (12).

In the present study, sequence-specific siRNA targeting TGF- $\beta 1$ mRNA was constructed and transfected into human embryonic lung fibroblast HFL-I cells. The target oligonucleotide fragments were confirmed to have been cloned into the pRNAT plasmid vector, as expected using an enzyme digestion and sequence reaction. Compared with the control group, the mRNA expression and protein levels of TGF- $\beta 1$ were found to be significantly inhibited by qPCR and ELISA, respectively. The results of the Annexin $\mathrm{V}$ apoptosis detection assay suggested that the marked increase in HFL-I cell apoptosis was caused by TGF- $\beta 1$-siRNA transfection. Taken altogether, the constructed TGF- $\beta 1$-siRNA plasmid demonstrated significant interference effects in vitro.

The in vivo investigation further demonstrated that radiation significantly elevated the mRNA expression and protein levels of TGF- $\beta 1$ in the lung of mice, indicating that TGF- $\beta 1$ is important in the genesis and development of radiation-induced lung injury. Previous studies have demonstrated that lung fibrosis is inhibited by inhibiting the TGF- $\beta 1$ signaling pathway or the application of TGF- $\beta 1$ monoclonal antibodies (13). In the present study, the above-mentioned functional TGF- $\beta 1$-siRNA was used in a rodent model of radiation-induced lung injury. The results revealed that radiation-induced pulmonary edema and alveolar inflammation were significantly relieved and the mRNA expression levels of TGF- $\beta 1$ were downregulated in the irradiated mice transfected with TGF- $\beta 1$-siRNA compared with the irradiated mice without transfection or transfected with empty vectors. These results suggested that the TGF- $\beta 1$-siRNA vector had protective effects against radiation-induced lung injury, possibly by inhibiting the expression of TGF- $\beta 1$. In conclusion, the specific TGF- $\beta 1$-siRNA vector effectively reduced the expression of TGF- $\beta 1$ and thereby inhibited the inflammatory response during radiation-induced pulmonary injury, which may assist in identifying novel techniques to prevent radiation-induced lung injury and fibrosis.

\section{Acknowledgements}

This study was funded by the Natural Science Foundation of Jiangsu Province (no. BK2009102), the National Natural Science Foundation of China (nos. 81402518 and 81472920), the Jiangsu Provincial Special Program of Medical Science (no. BL2012046), the Changzhou Scientific Program (nos. ZD200818, CE20125026, CE20135050, CJ20112019 and ZD201315) and the Open Program of Jiangsu Provincial Key Laboratory of Radiation Medicine and Protection (nos. KJS1241 and KJS1242).

\section{References}

1. Anscher MS, Marks LB, Shafman TD, et al: Risk of long-term complications after TFG-beta1-guided very-high-dose thoracic radiotherapy. Int J Radiat Oncol Biol Phys 56: 988-995, 2003.

2. Novakova-Jiresova A, Van Gameren MM, Coppes RP, Kampinga $\mathrm{HH}$ and Groen $\mathrm{HJ}$ : Transforming growth factor-beta plasma dynamics and post-irradiation lung injury in lung cancer patients. Radiother Oncol 71: 183-189, 2004.

3. Fire A, Xu S, Montgomery MK, Kostas SA, Driver SE and Mello CC: Potent and specific genetic interference by double stranded RNA in Caenorhabditis elegans. Nature 391: 806-811, 1998

4. Reynolds A, Leake D, Boese Q, Scaringe S, Marshall WS and Khvorova A: Rational siRNA design for RNA interference. Nat Biotechnol 22: 326-330, 2004.

5. Schallenkamp JM, Miller RC, Brinkmann DH, Foote T and Garces YI: Incidence of radiation pneumonitis after thoracic irradiation: Dose volume correlates. Int J Radiat Oncol Biol Phys 67: 410-416, 2007.

6. Kim SH, Lim DJ, Chung YG, Cho TH, Lim SJ, Kim WJ and Suh JK: Expression of TNF-alpha and TGF-beta 1 in the rat brain after a single high-dose irradiation. J Korean Med Sci 17: 242-248, 2002.

7. Evans ES, Kocak Z, Zhou SM, et al: Does transforming growth factor betal predict for radiation induced pneumonitis in patients treated for lung cancer. Cytokine 35: 186-192, 2006.

8. Chen Y, Williams J, Ding I, et al: Radiation pneumonitis and early circulatory cytokine markers. Semin Radiat Oncol 12: S26-S33, 2002

9. Nagashio Y, Ueno H, Imamura M, et al: Inhibition of transforming growth factor beta decreases pancreatic fibrosis and protects the pancreas against chronic injury in mice. Lab Invest 84: 1610-1618, 2004

10. Martin M, Lefaix JL and Delanian S: TGF-beta1 and radiation fibrosis: a master switch and a specific therapeutic target? Int J Radiant Oncol Biol Phys 47: 277-290, 2000.

11. Chiang CS, Liu WC, Jung SM, et al: Compartmental responses after thoracic irradiation of mice: strain differences. Int J Radiat Oncol Biol Phys 62: 862-871, 2005.

12. Volarevic M, Smolic R, Wu CH and Wu GY: Potential role of RNAi in the treatment of HCV infection. Expert Rev Anti Infect Ther 5: 823-831, 2007.

13. Shimizukawa M, Ebina M, Narumi K, Kikuchi T, Munakata $H$ and Nukiwa T: Intratracheal gene transfer of decorin reduces subpleural fibroproliferation induced by bleomycin. Am J Physiol Lung Cell Mol Physiol 284: L526-L532, 2003. 